\title{
Mathematics in paper
}

\section{Jari Hämäläinen*}

${ }^{\text {*Correspondence: }}$
jari.hamalainen@lut.fi
Centre of Computational
Engineering and Integrated Design
(CEID) and Department of
Mathematics and Physics,
Lappeenranta University of
Technology, P.O. Box 20,
Lappeenranta, FI-53851, Finland

Lappeenranta, FI-53851, Finland

\begin{abstract}
This paper aims to give a general overview of industrial mathematics applied to papermaking. Modelling challenges vary from computational fluid dynamics (CFD) to finite-element analyses (FEA) when the paper web transforms from a multiphase flow to a solid fibre network - to a ready paper. Also, different length scales are present from fibre level to machine level problems, i.e. from millimetres up to one hundred metres. Mathematical modelling of papermaking is aiming at optimizing the process and the end-product. Thus, computational tools for optimal shape design and optimal control purposes have been developed.
\end{abstract}

\section{Introduction}

We write and read mathematics on paper but we seldom think about what mathematics there is in paper, that is, what mathematics is behind papermaking. Paper is made from wood fibres mixed in water with some chemical and filler ingredients called as fibre suspension. A modern paper machine is producing a two kilometres long and ten metres wide paper web in a minute with extremely evenly distributed solid materials (see Figure 1). A papermaking production line begins from a so-called headbox which distributes a dilute ( $1 \%$ solids content) fibre suspension coming from a pump evenly across the width of a paper machine. A ten metre wide and one centimetre thick free jet flies from a headbox to a forming section between porous wires and most of water are removed in fractions of a second. After mechanical dewatering the solid contents of a wet paper web increases up to $50 \%$. The rest of water is removed by evaporation in a drying section. Paper machines vary depending on paper grades they produce, that is, a paper machine for tissue paper is different from a machine for copy paper or newspaper, but the basic concept is the same from a headbox to a dryer.

\section{Mathematical modelling of fibre suspension flows in multiple scales}

Modelling approaches vary a lot depending on a length scale we are dealing with [1] (see Figure 2). Here, the small scale means the fibre length which is 1-2 millimetres when considering fibre suspension flows. Or, when the structure of a single fibre is studied, then we are talking about orders of magnitude smaller scales. Indeed, one trend today in pulp and paper industry is to refine fibres to micrometre particles. The other extreme is the mill-level scale when the whole paper mill is considered. A fibre suspension flow can be modelled by using either a Lagrangian or an Eulerian multi-phase approach. A flow of tens of thousands of fibres can be simulated with Lagrangian methods but only in a small volume, $1 \mathrm{~cm}^{3}$, say. When dealing with unit processes like the headbox, this approach is not practical anymore. Thus, averaging is needed resulting in Eulerian multi-phase flow

@ 2012 Hämäläinen; licensee Springer. This is an Open Access article distributed under the terms of the Creative Commons Attribution License (http://creativecommons.org/licenses/by/2.0), which permits unrestricted use, distribution, and reproduction in any medium, provided the original work is properly cited. 


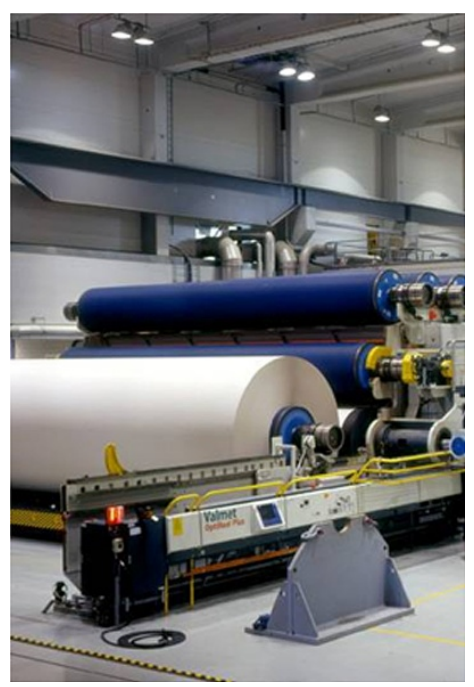

Figure 1 The dry-end view of a modern paper machine.

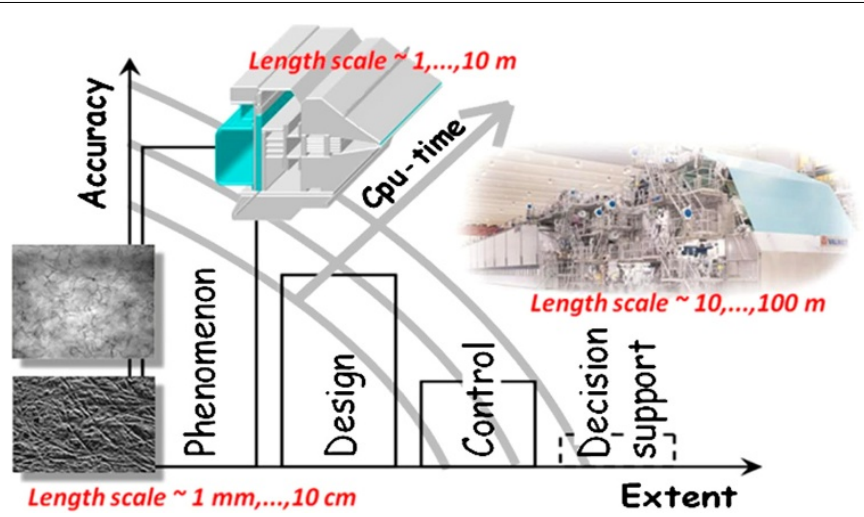

Figure 2 Mathematical modelling of fibre suspension flows and paper machine processes in different scales.

models or rheological models for the mixture. Specific mathematical models have also been developed for certain phenomena, namely to fibre orientation and fibre flocculation. All this is further complicated with the presence of turbulence interacting with the fibre phase.

\section{Optimized fluid flows}

Whenever a process is modelled, it is also tried to be optimized to some extent in every-day R\&D actions. The first immediate optimization application in papermaking is the optimal shape design of the headbox such that it distributes the flow evenly on a ten metre wide forming section resulting in even solid material and weight profile of a paper web. Furthermore, a wrong fibre alignment in thickness-directional layers in a web causes undesired end-properties of the paper sheet produced. Problems in copy machines or printing processes are typically caused by cockling and curling of paper, which in turn, are caused by non-optimal fibre orientations in a paper sheet (see Figure 3). 


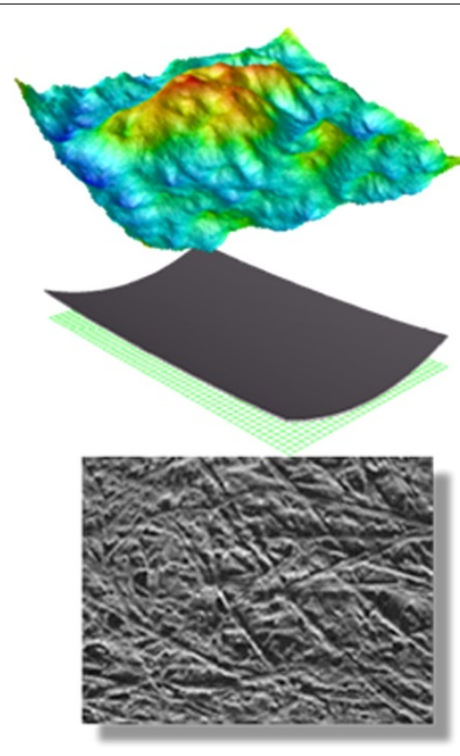

Figure 3 Curling and cockling of a paper sheet due to moisture expansion of non-optimally oriented fibres in paper.

From a mathematical point of view, the optimal shape design and optimal control of a headbox leads to CFD-based optimization [2]. Optimization software tools have been developed for the headbox, both for shape and control purposes. The optimal shape design tool can be computationally more expensive because the optimal design needs to be found only once for a certain industrial application and there are not any specific time limitations. But, computational time is limited when using CFD-based optimization for control purposes. Otherwise, the control actions take place too late. One such optimal control software called HOCS Fibre has been developed by world-leading machine supplier Metso Paper Inc. (www.metso.com) and computational technology enterprise $\mathrm{Nu}$ merola (www.numerola.fi). The software tool is not used for on-line control system at the moment, but off-line for trouble-shooting purposes [3]. It is based on depth-averaged two-dimensional Navier-Stokes equations and adjoint state technique in gradient-based optimization. One cost function evaluation, i.e., one flow field simulation, takes a few seconds in HOCS Fibre when full three-dimensional Navier-Stokes solution takes hours. HOCS Fibre has been used to tens of paper mills and the results are illustrated in Figure 4. The red markers illustrate the fibre orientation misalignment before optimization and the green markers after optimization. These are measured from a ready paper before and after HOCS Fibre optimizations.

There are also aims to model the whole paper mill and to optimize it. Now, it is not anymore so clear what optimal means, that is, there are plenty of objectives to be considered simultaneously. This leads to multi-objective optimization which is a basis for decisionsupport systems for papermaking [4]. Mathematical models of the whole mill are further simplified from the model of the headbox fluid flow optimizers. In addition, paper quality parameters are also prediction based on statistical correlations derived from measured data. So, there are tens of algebraic correlations in addition to first-principle process models. 


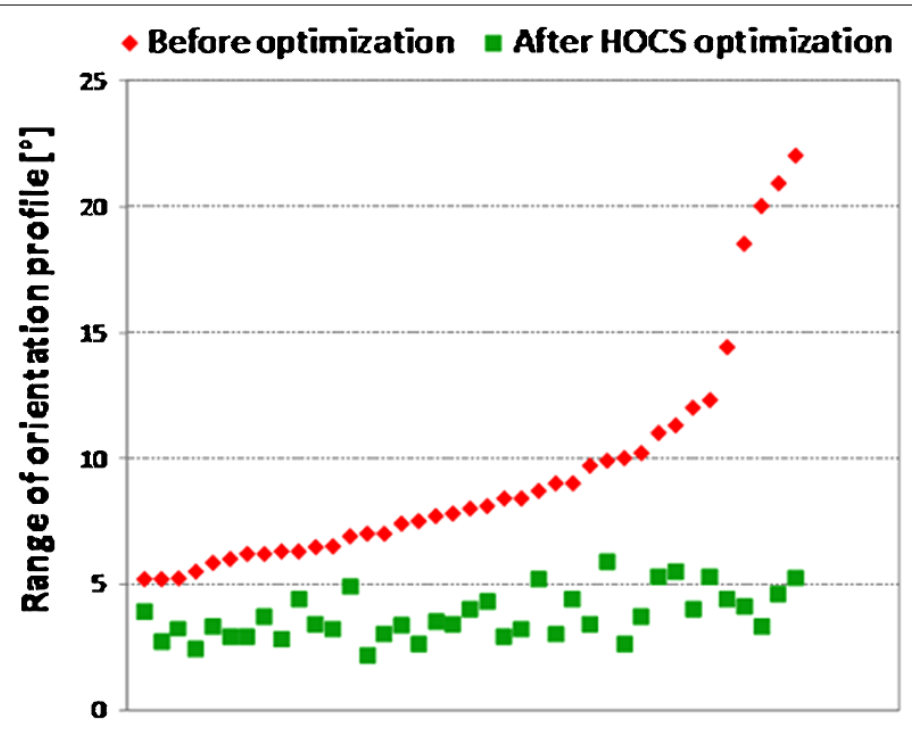

Figure 4 Min-max ranges of fibre orientation angles before and after optimization. Both are measured values in mill conditions.

These optimization examples illustrate that there are not 'good' or 'bad' models, but different levels of complexity can be used in different applications.

\section{From rheology of fluids to rheology of solids}

High-concentration fibre suspension can be considered as a generalized-Newtonian fluid obeying a shear-thinning viscosity model. It may also include memory effects. Rheological behaviour can also be detected for a ready paper [5]. Several studies have shown that a paper sheet is an elasto-visco-plastic material. And, mechanical properties and corresponding material parameters of the paper depend strongly on the fibrous structure of the paper sheet, which in turn, has been determined by fluid dynamics in the beginning of the papermaking process, in the headbox.

\section{Concluding remarks}

Papermaking is full of mathematics. Some examples of fluid dynamical and solid mechanical modelling were given in this article. Model-based optimization tools are also natural applications for mathematical models. But, plenty of mathematical modelling of papermaking was left out, e.g. the whole papermaking chemistry as well as free-surface flows, fluid-structure interactions (FSI) and phase-change problems (e.g. evaporation). And, totally different area of mathematics is the economy of papermaking. Pulp and paper industry is facing outstanding challenges in reducing investment and operating costs while aiming at top-quality products and increased production. Today this is further challenged by competition of raw materials with bio-energy and bio-fuel productions and other new wood-based products.

When you are writing mathematical formulae on a paper sheet next time, you may remember that there is already a lot of mathematics in the paper sheet. 
Received: 6 July 2012 Accepted: 27 July 2012 Published: 6 August 2012

References

1. Hämäläinen J, Lindström S, Hämäläinen T, Niskanen H: Papermaking fibre suspension flow simulations at multiple scales. J Eng Math 2011, 71(1):55-79.

2. Hämäläinen J, Hämäläinen T, Madetoja E, Ruotsalainen H: CFD-based optimization for complete industrial process: papermaking. In Optimization and Computational Fluid Dynamics. Edited by Thevenin, D, Janiga, G. Berlin: Springer 2008.

3. Avikainen M, Hämäläinen J, Tarvainen P: HOCS Fibre: CFD-based software for fibre orientation profile optimization for conventional and dilution headboxes. Nord Pulp Pap Res J 2010, 25(4):456-462.

4. Hämäläinen J, Madetoja E, Ruotsalainen H: Simulation-based optimization and decision support for conflicting objectives in papermaking. Nord Pulp Pap Res $J$ 2010, 25(3):405-410.

5. Hämäläinen J, Eskola R, Erkkilä A-L, Leppänen T: Rheology in papermaking - from fibre suspension flows to mechanics of solid paper. Korea-Australia Rheol J 2011, 23(4):211-217.

doi:10.1186/2190-5983-2-2

Cite this article as: Hämäläinen: Mathematics in paper. Journal of Mathematics in Industry 2012 2:2.

\section{Submit your manuscript to a SpringerOpen ${ }^{\circ}$ journal and benefit from:}

- Convenient online submission

- Rigorous peer review

- Immediate publication on acceptance

Open access: articles freely available online

- High visibility within the field

- Retaining the copyright to your article 